\title{
Atrial matrix remodeling in atrial fibrillation patients with aortic stenosis
}

\author{
Mariana Fragão-Marques ${ }^{1,2^{*}}$ (D) I. Miranda ${ }^{1}$, D. Martins ${ }^{1}$, I. Barroso ${ }^{2,4}$, C. Mendes ${ }^{1}$, A. Pereira-Neves ${ }^{3}$, \\ I. Falcão-Pires ${ }^{1}$ and A. Leite-Moreira ${ }^{1}$
}

\begin{abstract}
Background: This study aimed to evaluate atrium extracellular matrix remodeling in atrial fibrillation (AF) patients with severe aortic stenosis, through histological fibrosis quantification and extracellular matrix gene expression analysis, as well as serum quantification of selected protein targets.

Methods: A posthoc analysis of a prospective study was performed in a cohort of aortic stenosis patients. Between 2014 and 2019, 56 patients with severe aortic stenosis submitted to aortic valve replacement surgery in a tertiary hospital were selected.

Results: Fibrosis was significantly increased in the AF group when compared to sinus rhythm (SR) patients $(p=0.024)$. Moreover, cardiomyocyte area was significantly higher in AF patients versus SR patients $(p=0.008)$. Conversely, collagen III gene expression was increased in AF patients $(p=0.038)$. TIMP1 was less expressed in the atria of AF patients. MMP16/TIMP4 ratio was significantly decreased in AF patients $(p=0.006)$. TIMP1 $(p=0.004)$ and TIMP2 ( $p=0.012)$ were significantly increased in the serum of AF patients. Aortic valve maximum $(p=0.0159)$ and mean $(p=0.031)$ gradients demonstrated a negative association with serum TIMP1.
\end{abstract}

Conclusions: Atrial fibrillation patients with severe aortic stenosis present increased atrial fibrosis and collagen type III synthesis, with extracellular matrix remodelling demonstrated by a decrease in the MMP16/TIMP4 ratio, along with an increased serum TIMP1 and TIMP2 proteins.

Keywords: Atrial fibrillation, Aortic stenosis, Fibrosis, Atrial remodeling, Biomarkers

\section{Background}

Atrial fibrillation (AF) is the most common cardiac arrhythmia with adverse clinical outcomes and diverse pathophysiological background [1]. AF affects approximately 20.9 million men and 12.6 million women worldwide, representing a 1.5 -fold and two-fold increase in all-cause mortality, respectively [2].

Aortic stenosis is the most prevalent valvular disease, with aortic valve replacement (AVR) surgery remaining

*Correspondence: marianaifrm@gmail.com

${ }^{1}$ Cardiovascular Research and Development Center, Faculty of Medicine,

University of Porto, Alameda Professor Hernani Monteiro, 4200 Porto,

Portugal

Full list of author information is available at the end of the article the gold standard treatment for severe symptomatic aortic stenosis, improving both quality of life and overall survival [3]. Owing to ageing demographics, aortic stenosis has been increasing over the past decades, presenting an AF prevalence of $35.6 \%$ in a multicentre prospective registry of aortic stenosis patients $[4,5]$. However, the pathophysiology of AF in aortic stenosis is poorly understood. AF pathophysiology begins with ectopic firing and re-entry, which depend on several mechanisms: (1) ion channel dysfunction; (2) $\mathrm{Ca}^{2+}$-handling abnormalities; (3) structural remodelling; (4) autonomic neural dysregulation. Regarding ion channel dysfunction, cardiomyocytes return to their resting potential after depolarization through an equilibrium between If (pacemaker) and Ik1 (inward rectifier $\mathrm{k}+$ ) currents, which might be

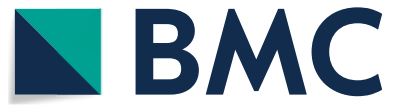

(c) The Author(s) 2020. Open Access This article is licensed under a Creative Commons Attribution 4.0 International License, which permits use, sharing, adaptation, distribution and reproduction in any medium or format, as long as you give appropriate credit to the original author(s) and the source, provide a link to the Creative Commons licence, and indicate if changes were made. The images or other third party material in this article are included in the article's Creative Commons licence, unless indicated otherwise in a credit line to the material. If material is not included in the article's Creative Commons licence and your intended use is not permitted by statutory regulation or exceeds the permitted use, you will need to obtain permission directly from the copyright holder. To view a copy of this licence, visit http://creativecommons.org/licenses/by/4.0/. The Creative Commons Public Domain Dedication waiver (http://creativeco mmons.org/publicdomain/zero/1.0/) applies to the data made available in this article, unless otherwise stated in a credit line to the data. 
dysfunctional in AF. In addition, early afterdepolarizations (EADs) and delayed afterdepolarizations (DADs), most likely related to $\mathrm{Ca}^{2+}$-handling abnormalities, may contribute significantly to AF pathogenesis [6]. Structural and electrical remodelling is core to most forms of AF, particularly in the more permanent ones [7]. Concerning structural remodelling, atrial fibrosis is key and alters cardiomyocyte electrical coupling due to misplacing and changing the structure of connexins, thus inducing fragmented electrical conduction [8]. Evidence suggests atrial remodeling is associated with disease occurrence and progression, which involves specific molecular markers of fibrosis such as Tissue Inhibitor of Metalloproteinase (TIMP) 1, Matrix Metalloproteinase (MMP) 9 and Collagen type 1 Carboxy-terminal Peptide (CICP), with diverse contributions according to different AF subtypes [1]. These biomarkers appear to increase with higher arrhythmia burden [1]. Increased afterload is associated with AF and myocardial fibrosis [5] and while TIMP-1 has been reported to increase, MMP1 was shown to decrease in AF patients' serum [9]. Conversely, atrium TIMP-4 in AF patients with rheumatic heart disease was lower when compared with Sinus Rhythm (SR) patients, while MMP-2, type I, and type II collagen were increased in the AF group [10].

This is the first study aimed to characterize atrial fibrosis in AF patients with aortic stenosis submitted to AVR surgery, as well as evaluate the gene expression profile of several extracellular matrix proteins and quantify differentially expressed targets in the serum of AF patients.

\section{Methods}

This study aimed to evaluate atrium extracellular matrix remodeling in AF patients with severe aortic stenosis, through histological fibrosis quantification and extracellular matrix gene expression analysis of an array of genes: collagen I and III, TIMP 1, TIMP2, TIMP4, MMP 2, MMP9, MMP16, and TGF- $\beta 1$. Serum quantification of target extracellular matrix proteins was performed to establish potential AF biomarkers (TIMP1 and TIMP2).

\section{Study design}

This study represents a posthoc analysis of a prospective study on a cohort of aortic stenosis patients. Between 2014 and 2019, 56 patients with severe aortic stenosis submitted to AVR surgery in a tertiary hospital were selected. Their baseline clinical and echocardiography data were recorded, and serum and atrium samples were collected. Reoperations and emergent cases were excluded, as well as patients with severe aortic regurgitation. The recruited patients were then grouped according to their cardiac rhythm status: AF or SR $(\mathrm{N}=15$ and $\mathrm{N}=42$, respectively) (see below).
The investigation conforms with the principles outlined in the Declaration of Helsinki. The protocol was approved by the institution's ethics committee and data confidentiality was assured. All participants gave written informed consent.

\section{Data collection}

Chronic Kidney Disease was considered when baseline creatinine levels exceeded $1.5 \mathrm{mg} / \mathrm{dL}$. New York Heart Association (NYHA) functional classification was used to characterize heart failure symptoms. Coronary Artery Disease (CAD) was considered when previous myocardial infarction was reported and/or invasive coronary angiography reported stenosis $>50 \%$. Cerebrovascular disease was defined based on a history of stroke or transitory ischemic attack or a reported stenosis $>50 \%$ on carotid doppler ultrasonography. Smoking was considered when patients reported being active smokers or past smokers within less than a year of cessation. Patients underwent an echocardiographic evaluation performed by experienced operators up to 6 months before surgery. Cardiac chamber dimensions and volumes were measured as recommended and systolic function was accessed by evaluation of left ventricular ejection fraction, using the modified Simpson rule from biplane 4 and 2 chamber views [11]. Reduced ejection fraction was considered below $40 \%$, according to the European Society of Cardiology guidelines [12] Left atrium enlargement was considered when left atrium diameter was equal or superior to $40 \mathrm{~mm}$.

As previously mentioned, patients were divided into SR and AF groups. All patients had an electrocardiogram (EKG) performed up to 6 months prior to surgery and AF was defined according to international guidelines as absolutely irregular RR intervals and no discernible, distinct $\mathrm{P}$ waves, with an episode lasting at least $30 \mathrm{~s}$ being the threshold for diagnostic purposes [2]. Definitions of paroxysmal, persistent, long-standing persistent or permanent AF followed the European Society of Cardiology guidelines. Two patients presented with paroxysmal AF (13.3\%), 8 with permanent AF (53.3\%) and 5 with persistent $\mathrm{AF}(33.3 \%)$ [2].

\section{Biopsy and serum sample collection}

During surgery, an atrium appendix myocardial biopsy was collected, and the sample was either immediately fixed in formalin (formalin solution, neutral buffered, $10 \%)$ and processed for histological analysis or flashfrozen in liquid nitrogen and stored at $-80^{\circ} \mathrm{C}$ for posterior gene expression analysis. Whole blood samples were collected at the same timepoint and immediately centrifuged at $3000 \mathrm{rpm}$ for $10 \mathrm{~min}$; serum was stored 
at $-80{ }^{\circ} \mathrm{C}$ for further Enzyme-Linked ImmunoSorbent Assay (ELISA).

\section{Histomorphometric quantification}

All samples were processed using Leica Histocore Pearl automatic processor. A total of $29(\mathrm{SR} \mathrm{N}=19, \mathrm{AF} \mathrm{N}=10)$ and 18 patients $(\mathrm{SR} N=13, \mathrm{AF}=5)$ were used to assess fibrosis and cardiomyocyte cross-sectional area, respectively. Paraffin inclusion was performed in Leica Histocore Arcardia Embedding System. Sections of $3 \mu \mathrm{m}$ were cut and stained with hematoxylin-eosin (Harris hematoxylin and alcoholic eosin) for assessing cardiomyocyte cross-sectional area using Leitz Wetzlar-Dialux 20 microscopy and coupled camera (Olympus XC30). At least 60 cardiomyocytes were counted using the $250 \times$ amplification; fibrosis was assessed using $3 \mu \mathrm{m}$ atrial sections stained with Red Sirius and quantification was performed with Image-Pro Plus in 8 fields per sample using the $100 \times$ amplification (results presented as percentage of the total area of each section).

\section{Gene expression analysis}

A total of 19 patients (SR N=11, AF $\mathrm{N}=8$ ) were evaluated for the gene expression of several extracellular matrix proteins: collagen I and III, TIMP1, TIMP2, TIMP4, MMP2, MMP9, MMP16 and Transforming Growth Factor $\beta 1$ (TGF- $\beta 1$ ). RNA extraction was performed using a TRIzol protocol following the manufacturer's instructions. Briefly, tissue cells were disrupted in TRIizol reagent using $1.4 \mathrm{~mm}$ beads (Minilys, Bertin). After adding chloroform and centrifugation at $14,000 \mathrm{rpm}$, at $4{ }^{\circ} \mathrm{C}$, for $15 \mathrm{~min}$, RNA was extracted and precipitated in isopropanol. RNA was washed in 70\% ethanol and resuspended in Tris $10 \mathrm{mM}$. RNA concentration and integrity were assessed both in the Nanodrop and by electrophoresis. cDNA $(100 \mathrm{ng} / \mu \mathrm{L})$ was synthesized using the SensiFAST ${ }^{\mathrm{TM}}$ cDNA Synthesis Kit (Bioline). Reactions were performed in a Bio-Rad T100 thermal cycler using the following protocol: $10 \mathrm{~min}$ of primer annealing at $25^{\circ} \mathrm{C}$ followed by reverse transcription for $15 \mathrm{~min}$ at $42{ }^{\circ} \mathrm{C}$, followed by $5 \mathrm{~min}$ at $85^{\circ} \mathrm{C}$ to inactivate reverse transcriptase. Quantitative polymerase chain reaction (qPCR) reactions were run in triplicate in $10 \mu \mathrm{L}$ containing the following: $1 \mu \mathrm{L}$ sample cDNA, $5 \mu \mathrm{L}$ $2 \times$ SensiFAST $^{\text {TM }}$ SYBR Hi-ROX Mix (Bioline), and $0.4 \mu \mathrm{L}$ primers. RT-qPCR reactions were performed using the PikoReal $^{\mathrm{TM}}$ Real-Time PCR System (Thermo Scientific ${ }^{\mathrm{TM}}$ ) using the following protocol: polymerase was activated for $3 \mathrm{~min}$ at $95^{\circ} \mathrm{C}$ followed by 40 cycles of denaturation for $15 \mathrm{~s}$ at $95{ }^{\circ} \mathrm{C}$, annealing for $30 \mathrm{~s}$ at $60{ }^{\circ} \mathrm{C}$, and extension for $30 \mathrm{~s}$ at $72{ }^{\circ} \mathrm{C}$. Thereafter, melting curve analysis from 65 to $95{ }^{\circ} \mathrm{C}$ in $0,5{ }^{\circ} \mathrm{C}$ increments was performed. Prior to gene expression quantification using the $2^{-\Delta \mathrm{CT}}$ method, PCR efficiency of each gene including the internal control gene (18s RNA) was determined and it was assured that they were identical. Primer sequences are presented in Table 1.

Target gene expression was normalized to the $18 \mathrm{~S}$ gene. Initial mRNA expression data were logarithm transformed using the $2^{-\Delta \mathrm{C}}{ }_{\mathrm{T}}$ method [13].

\section{Serum quantification}

After gene expression analysis, a total of 24 patients (SR $\mathrm{N}=17$, AF $\mathrm{N}=7$ ) were selected for assessing serum quantification of proteins whose genes were shown to be increased by reverse transcription (RT)-PCR in AF patients (TIMP1 and 2, see below). ELISA assays were performed following the manufacturer's instructions (Abcam, ab187394 Human TIMP-1 SimpleStep ELISA Kit, and ab100653 TIMP2 Human ELISA kit).

\section{Statistical analysis}

IBM SPSS Statistics version 25 was used for all statistical analyses. Categorical variables were presented as percentages and continuous variables as mean and standard deviation (sd). Categorical variables were analysed using the Chi-squared test or Fisher's exact test when appropriate and continuous variables were analysed with a t-test for independent samples. Linear regression was performed to correlate continuous variables and results are

\section{Table 1 Primers used in this study}

\begin{tabular}{|c|c|}
\hline Primer name & Primer sequences $\left(5^{\prime}\right.$ to $\left.3^{\prime}\right)$ \\
\hline HsCOL1A1_F1 & CTCTGGTCCTCGTGGTCT \\
\hline HsCOL1A1_R1 & ССССАТСАТСТССАТТСТTТСС \\
\hline HsCOL3A1_F1 & GGTGCTAATGGTGCTCCT \\
\hline HsCOL3A1_R1 & TCCTTGCCATCTTCGCCTTT \\
\hline HsMMP2_F & TTGGTGGGAACTCAGAAGGT \\
\hline HsMMP2_R & GTCATCATCGTAGTTGGCTGTG \\
\hline HsMMP9_F & CTGCCACTTCCCCTTCATC \\
\hline HsMMP9_R & GGTCGTCGGTGTCGTAGT \\
\hline HsMMP16_F & TGACCCCAGAATGTCAGTGC \\
\hline HsMMP16_R & GGGGCTTCTTCATCCAGTCAA \\
\hline HsTIMP1_F & CTGTTGGCTGTGAGGAATGC \\
\hline HsTIMP1_R & AGGTGACGGGACTGGAAG \\
\hline HsTIMP2_F & GAGCACCACCCAGAAGAAG \\
\hline HsTIMP2_R & CAGTCCATCCAGAGGCAC \\
\hline HsTIMP4_F & GACCCTGCTGACACTGAAAA \\
\hline HsTIMP4_R & CTTCTGGCTGTTGGCTTCTA \\
\hline HsTGFB1_F & GAAGAACTGCTGCGTGCG \\
\hline HsTGFB1_R & GTGTCCAGGCTCCAAATGT \\
\hline Hs18s_F2 & GACTCAACACGGGAAACCTC \\
\hline Hs18s_R2 & CCAGACAAATCGCTCCACC \\
\hline
\end{tabular}

Primer name and respective base-pair sequence 
presented as $\beta$ coefficients, 95\% confidence intervals (CI), and $p$ values. Statistical significance was considered when $p<0.05$.

\section{Results}

\section{Patient demographics}

Participants had a mean age of $70.85 \pm 10.00$ years, with males representing $49.2 \%$ of patients. The most common comorbidity was hypertension, representing $64.4 \%$ of patients, while $20.3 \%$ had type 2 diabetes mellitus. Smoking habits were present in $8.5 \%$ of participants, although there was no chronic kidney disease in this cohort. Only 2 patients had a previous acute myocardial infarction (3.4\%), though $15.3 \%$ revealed coronary artery disease on coronary angiography. Moreover, 2 patients had a history of cerebrovascular disease (3.4\%). Symptoms of heart failure (NYHA > I) were present in $55.9 \%$ of patients, with NYHA class II being the most prevalent stage (54.2\%); $15.3 \%$ of patients suffered from angina, while only $5.1 \%$ had complaints of syncope or lipothymia. Solely one patient had decreased left ventricular ejection fraction. Nonetheless, $64.4 \%$ had increased left atrium diameter. Aortic valve stenosis was severe, with a mean aortic valve maximum gradient of $83.04 \pm 20.47 \mathrm{mmHg}$, an aortic valve mean gradient of $51.32 \pm 12.36 \mathrm{mmHg}$ and an aortic valve area of $0.76 \pm 0.16 \mathrm{~cm}^{2}$.

Concerning SR and AF patient subgroups, AF patients were older (AF $75.47 \pm 7.71$ vs SR $68.98 \pm 10.23$ years, $p=0.023)$. There were no other differences between groups regarding demographics, comorbidities, and echocardiographic data (Table 2).

\section{Atrial fibrillation \\ Histomorphometric analysis}

Fibrosis was significantly increased in the AF group when compared to SR patients, with a mean \pm SD percent fibrosis of $38 \pm 6 \%$ and $25 \pm 2 \%$, respectively $(p=0.024)$. Moreover, cardiomyocyte area was significantly higher in AF patients versus SR patients-334.1 $\pm 18.31 \mu \mathrm{m}^{2}$ versus $289.3 \pm 6.18 \mu \mathrm{m}^{2}(p=0.008)$ (Fig. 1$)$.

\section{Extracellular matrix gene expression analysis}

Collagen gene expression was evaluated to explore the differences in fibrosis observed through histologic examination. Atrial expression of collagen I was similar between groups $\left(2^{-\Delta \mathrm{CT}}\right)$ : AF $2.86 \times 10^{-5} \pm 7.03 \times 10^{-6}$ versus SR $1.67 \times 10^{-5} \pm 4.71 \times 10^{-6}(p=0.176)$. Conversely, collagen III gene expression was increased in AF patients: $1.46 \times 10^{-4} \pm 2.62 \times 10^{-5}$ versus $8.39 \times 10^{-5} \pm 1.11 \times 10^{-5}$ $(p=0.038)$. The collagen ratio I/III was, nonetheless, similar between AF and SR patients: $0.24 \pm 0.05$ versus $0.23 \pm 0.06(p=0.928)$. Data is depicted in Fig. 2 .
Table 2 Patient demographics

\begin{tabular}{|c|c|c|c|}
\hline Variable [n (\%)] & $\mathrm{SR}(\mathrm{N}=42)$ & $A F(N=15)$ & $p$ value \\
\hline Age, years [mean $\pm S D$ ] & $68.98 \pm 10.23$ & $75.47 \pm 7.71$ & 0.023 \\
\hline Gender (male) & $21(50.0)$ & $8(47.1)$ & 0.838 \\
\hline Smoking & $5(11.9)$ & $0(0)$ & 0.308 \\
\hline Diabetes mellitus (type 2) & $7(16.7)$ & $5(29.4)$ & 0.299 \\
\hline Hypertension & $28(66.7)$ & $10(62.5)$ & 0.765 \\
\hline Previous AMI & $2(4.8)$ & $0(0)$ & 1.000 \\
\hline Coronary artery disease & $7(17.1)$ & $2(12.5)$ & 1.000 \\
\hline Cerebrovascular disease & $1(2.4)$ & $1(6.3)$ & 0.479 \\
\hline NYHA class $>1$ & $23(63.9)$ & $10(66.7)$ & 0.850 \\
\hline Angina & $5(13.9)$ & $4(28.6)$ & 0.245 \\
\hline Syncope/lipothymia & $2(5.6)$ & $1(7.1)$ & 1.000 \\
\hline Ejection fraction & $0(0)$ & $1(7.1)$ & 0.280 \\
\hline Left atrium dilation & $26(81.3)$ & $12(92.3)$ & 0.654 \\
\hline AoV MaxG, mmHg [mean \pm SD] & $84.90 \pm 20.23$ & $78.93 \pm 21.14$ & 0.371 \\
\hline $\begin{array}{l}\text { AoV MeanG, mmHg } \\
\quad[\text { mean } \pm \text { SD }]\end{array}$ & $52.36 \pm 11.95$ & $48.86 \pm 13.41$ & 0.380 \\
\hline Aov area, $\mathrm{cm}^{2}[$ mean $\pm S D]$ & $0.76 \pm 0.16$ & $0.75 \pm 0.15$ & 0.784 \\
\hline
\end{tabular}

AMI acute myocardial infarction, NYHA New York Heart Association Functional Capacity Classification, AoV aortic valve, MaxG maximum gradient

A further analysis on extracellular matrix genes was performed, with several MMPs and TIMPs tested for their atrial expression. MMP2 expression analysis showed no differences between groups: AF $1.42 \times 10^{-}$ ${ }^{4} \pm 2.35 \times 10^{-5}$ versus SR $1.59 \times 10^{-4} \pm 1.40 \times 10^{-5}$ $(p=0.536)$. MMP9 and MMP16 were similar between patients, showing no differential atrial expression: $1.27 \times 10^{-6} \pm 2.77 \times 10^{-7}$ versus $1.57 \times 10^{-6} \pm 3.25 \times 10^{-}$ $7 \quad(p=0.509)$ and $4.35 \times 10^{-6} \pm 7.08 \times 10^{-7} \quad$ versus $5.86 \times 10^{-6} \pm 6.66 \times 10^{-7} \quad(p=0.141), \quad$ respectively. In addition, TGF $\beta 1$ gene expression analysis was similar between patient groups: $4.65 \times 10^{-5} \pm 5.75 \times 10^{-6}$ versus $5.96 \times 10^{-5} \pm 1.01 \times 10^{-5}(p=0.291)$ (Fig. 3). On the other hand, TIMP1 was less expressed in the atria of AF patients: $3.69 \times 10^{-4} \pm 5.82 \times 10^{-5}$ versus $5.72 \times 10^{-}$ ${ }^{4} \pm 7.41 \times 10^{-5} \quad(p=0.052)$. TIMP2 presented similar results, demonstrating a significantly decreased expression in the AF group: $2.37 \times 10^{-4} \pm 3.04 \times 10^{-5}$ versus $3.75 \times 10^{-4} \pm 4.37 \times 10^{-5}(p=0.026)$. Conversely, TIMP4 did not show differences between patients: $3.88 \times 10^{-}$ ${ }^{5} \pm 1.17 \times 10^{-5}$ versus $2.17 \times 10^{-5} \pm 4.06 \times 10^{-6}(p=0.167)$ (Fig. 4).

Moreover, well recognized ratios such as MMP2/ TIMP1, MMP2/TIMP2 and MMP9/TIMP1 were tested for their relationship with AF. MMP2/TIMP1 did not present differences between groups, with a ratio of $0.35 \pm 0.07$ in $\mathrm{AF}$ patients and $0.26 \pm 0.03$ in SR patients $(p=0.201)$. Likewise, both the MMP2/ TIMP2 and MMP9/TIMP1 ratios were similar between 

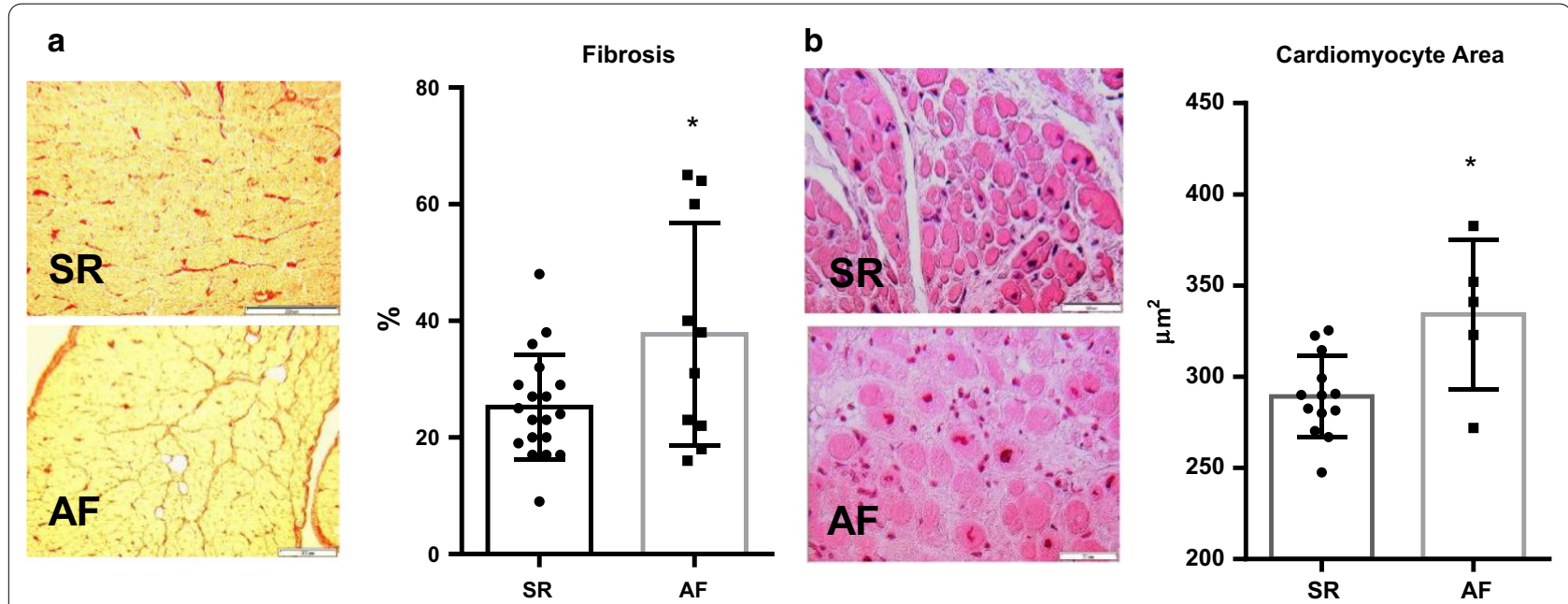

Fig. 1 a Fibrosis quantification by Sirius red stain — data and representative images of both AF and SR patient subgroups. b Cardiomyocyte area quantification by hematoxylin-eosin stain-data and representative images of AF and SR patients. ${ }^{*} p>0.05$
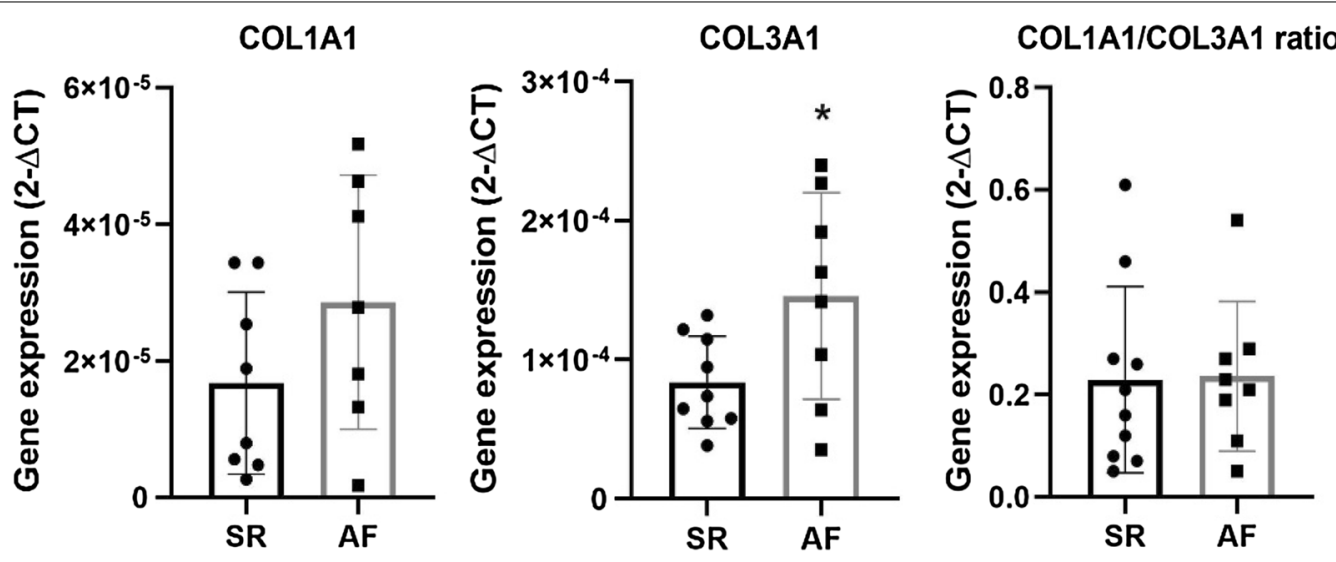

Fig. 2 Atrial gene expression of collagen type I, type III and respective ratio in both SR and AF patients. ${ }^{*} p<0.05$
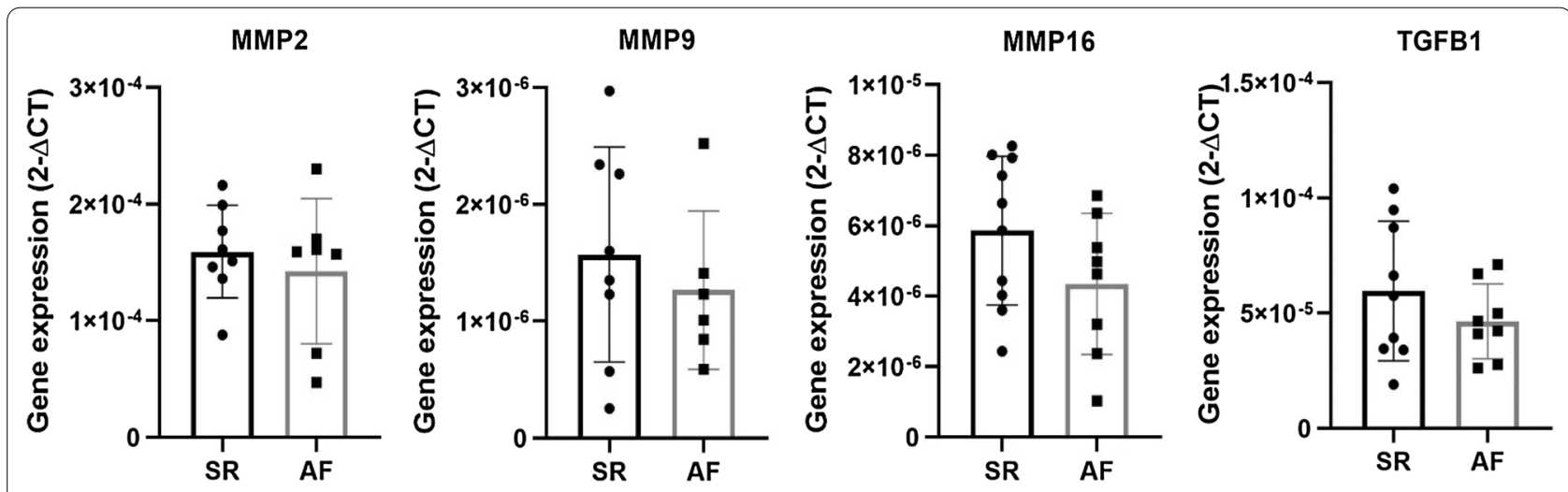

Fig. 3 Atrial gene expression of MMP2, MMP9, MMP16 and TGF $\beta$ in both SR and AF patients 

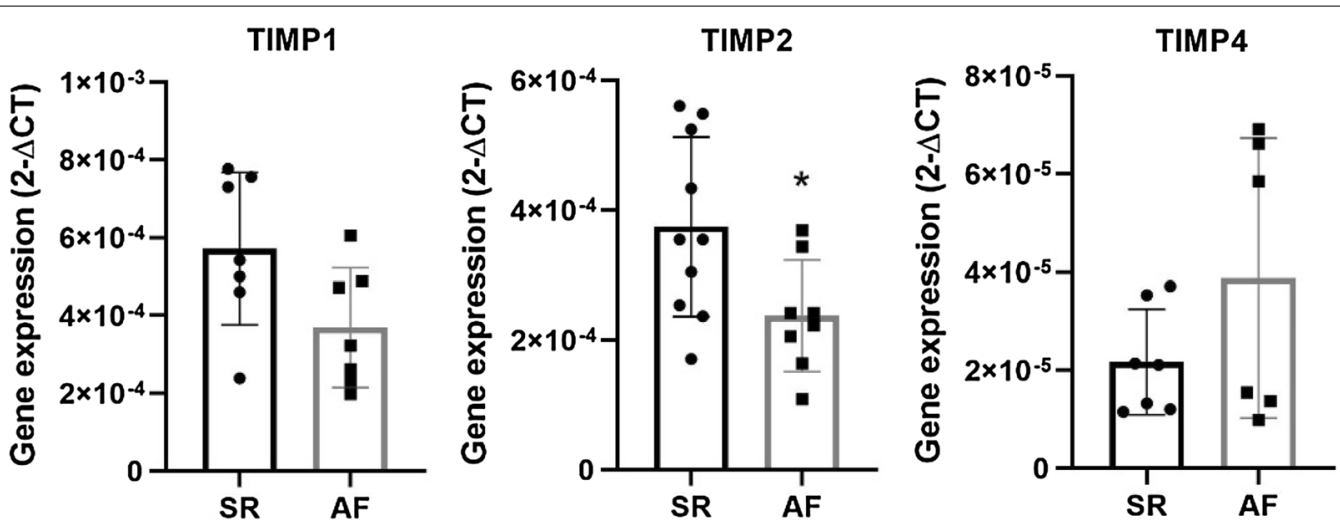

Fig. 4 Atrial gene expression of TIMP1, TIMP2 and TIMP4 in both SR and AF patients. ${ }^{*} p<0.05$

groups $-0.68 \pm 0.09$ versus $0.53 \pm 0.04 \quad(p=0.123)$ and $3.53 \times 10^{-3} \pm 9.30 \times 10^{-4}$ versus $2.10 \times 10^{-}$ ${ }^{3} \pm 3.02 \times 10^{-4} \quad(p=0.128)$. (Fig. 5). MMP2/TIMP4 and MMP16/TIMP4 ratios were also tested, with the former demonstrating a tendency towards significance $(3.87 \pm 1.22$ vs $7.96 \pm 1.58, p=0.063)$, while the latter was significantly decreased in AF patients $(0.07 \pm 0.02$ vs $0.24 \pm 0.05, p=0.006)$.

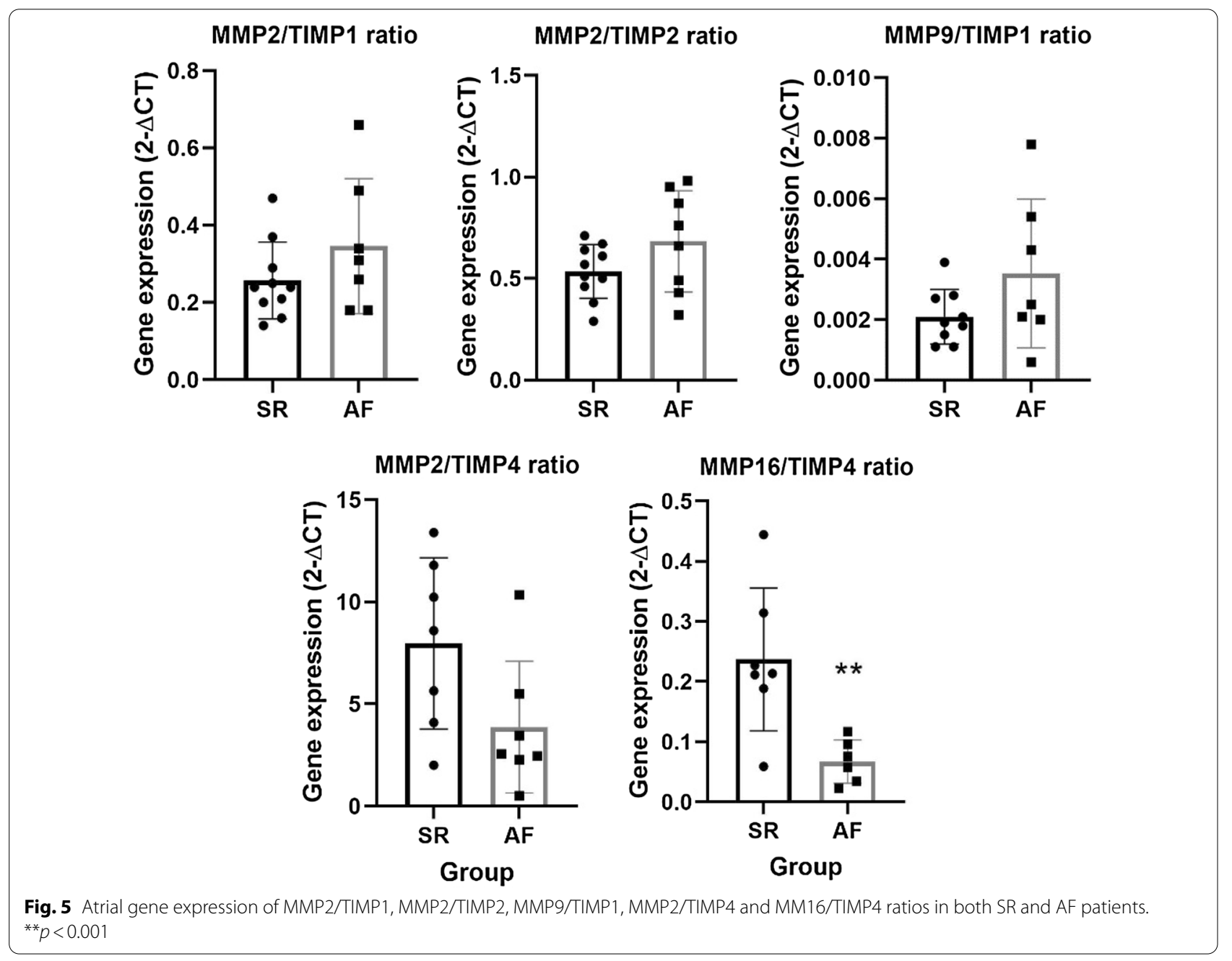




\section{Serum TIMP1 and TIMP2}

The counterpart proteins to the altered gene expression in AF patients (TIMP1 and TIMP2, $p=0.052$ and $p=0.026$, respectively) were quantified in the serum of both AF and SR patient groups. TIMP1 was significantly increased in the serum of AF patients: AF $6472.0 \pm 958.9 \mathrm{pg} / \mathrm{mL}$ versus SR $3612.0 \pm 385.4 \mathrm{pg} / \mathrm{mL}$ $(p=0.004)$. Similarly, TIMP2 was increased in the AF patient group: $144.2 \pm 30.6 \mathrm{pg} / \mathrm{mL}$ versus $93.4 \pm 5.7 \mathrm{pg} /$ $\mathrm{mL}(p=0.012)$ (Fig. 6).

\section{Aortic stenosis severity}

The severity of aortic stenosis was evaluated through aortic valve maximum and mean gradients, as well as aortic valve area. These predictors were correlated with histological parameters and extracellular matrix gene expression and serum proteins. Results are presented in Table 3.

\section{Histomorphometric analysis}

Neither the aortic valve maximum gradient $(p=0.920$ and $p=0.250)$ nor its mean gradient $(p=0.850$ and $p=0.421)$ correlated with fibrosis or atrial cardiomyocyte size, respectively. However, aortic valve area was negatively correlated with cardiomyocyte area-B coefficient [95\% CI] $-0.001\left[-0.002\right.$ to $\left.-2.6 \times 10^{-5}\right], p=0.043$ (Fig. 7). In addition, fibrosis was not correlated with aortic valve area $(p=0.251)$.

\section{Extracellular matrix gene expression analysis}

Aortic valve maximum gradient was inversely correlated with the expression of COL1A1 gene (B - 493,531.00 [ -929322.42 to $-57,739.00], p=0.029)$, as well as the COL1A1/3A1 gene expression ratio (B - 88.73 [ -165.76 to -11.71 ], $p=0.027$ ). (Fig. 8) Furthermore, MMP2/ TIMP1 ratio presented a tendency towards significance, with a B coefficient of -79.73 [ -159.87 to 0.42$]$,

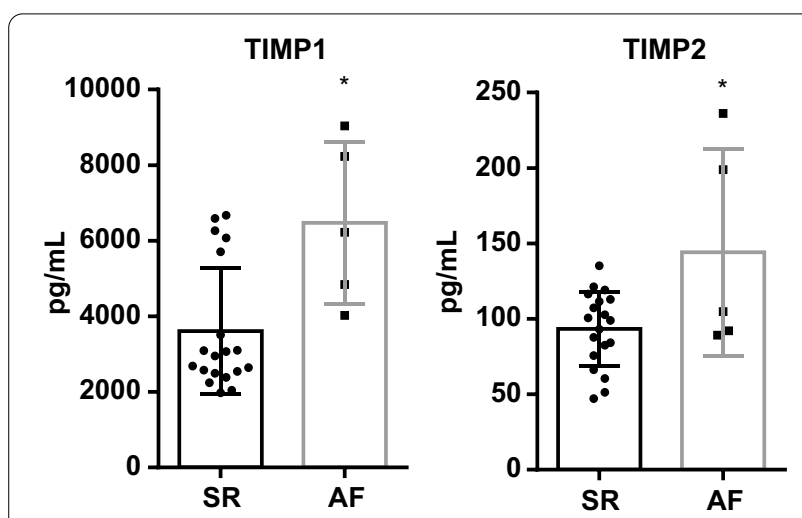

Fig. 6 Serum TIMP1 and TIMP2 proteins in both SR and AF patients. ${ }^{*} p<0.05$ $p=0.051$. The remaining extracellular genes were not correlated with aortic valve maximum gradient (Table 3).

Similarly, aortic valve mean gradient was negatively correlated with COL1A1 expression (B - 248,924.75 [ -492536.12 to -5313.37$], p=0.046)$, COL1A1/3A1 ratio $(\mathrm{B}-44.44[-87.66$ to -1.22$], p=0.045)$ and MMP2/TIMP1 ratio ( $\mathrm{B}-44.42$ [- 87.46 to -1.38$]$, $p=0.044$ ). (Fig. 9) Other matrix genes remained similar regardless of aortic valve mean gradient (Table 3 ).

Additionally, aortic valve area presented a positive correlation with the gene expression of COL1A1 (B 4045.91 [564.09-7527.72], $p=0.026)$ and COL1A1/3A1 ratio (B 0.68 [0.05-1.32], $p=0.037$ ) (Fig. 7), although other extracellular matrix genes presented no relation with valve area (Table 3).

\section{Serum TIMP1 and TIMP2}

Aortic valve maximum gradient demonstrated a negative association with serum TIMP1, with a B coefficient of -0.004 [ -0.006 to -0.001$], p=0.015$. (Fig. 8) Likewise, aortic valve mean gradient was negatively correlated with serum TIMP1-B $-0.002[-0.004$ to -0.0002$]$, $p=0.031$. (Fig. 9) No other associations were observed regarding aortic valve function and serum TIMP1 and TIMP2 (Table 3).

\section{Discussion}

This is the first study evaluating atrial remodelling in aortic stenosis patients with chronic AF, both fibrosis quantification and target extracellular matrix protein gene expression analysis. AF patients were older, had increased cardiomyocyte area and atrial fibrosis on histologic quantification, increased collagen type III gene expression, as well as decreased TIMP1 and TIMP2 gene expression. Moreover, MMP16/TIMP4 ratio was decreased in AF patients. Serum TIMP1 and TIMP2 proteins were both increased in the AF patient subgroup.

Aortic stenosis patients with AF were older than their SR counterparts. Age is the most common and consistently described risk factor for AF, regardless of the cardiovascular disease background $[4,14]$. Patients with AF had increased fibrosis, as demonstrated by histology sections, as well as increased cardiomyocyte size, suggested by the higher cell area. There is extensive evidence on the role of atrial fibrosis in sustaining the arrhythmia [15], although studies on aortic stenosis are scarce. Studies on animal models with increased afterload but absent hypertension suggest atrial remodeling increases AF inducibility through atrial myocardium fibrosis [16]. On the other hand, fibrosis evaluated by cardiac magnetic resonance imaging suggests a correlation with atrial fibrillation in hypertrophic cardiomyopathy [17]. Aortic stenosis causes pressure overload in both the ventricle and atrium, thus 
Table 3 Linear regressions comparing aortic stenosis severity with extracellular matrix remodeling

\begin{tabular}{|c|c|c|c|}
\hline Variable & B coefficient & $95 \% \mathrm{Cl}$ & $p$ value \\
\hline \multicolumn{4}{|l|}{ AoMaxG } \\
\hline Cardiomyocyte Area & 0.089 & {$[-0.069$ to 0.248$]$} & 0.250 \\
\hline Fibrosis & -8.431 & {$[-184.602$ to 167.741$]$} & 0.920 \\
\hline COLIA1 & $-493,530.998$ & [-929322.424 to - 57739] & 0.029 \\
\hline COL3A1 & $-106,482.445$ & [- 240598.920 to $27,634.031]$ & 0.110 \\
\hline COL1A1/3A1 Ratio & -88.731 & [ -165.756 to -11.706$]$ & 0.027 \\
\hline MMP2 & $-27,782.426$ & [ -170179.428 to $114,614.396]$ & 0.680 \\
\hline MMP9 & $-595,526.093$ & [- 1429715.173 to $238,662.988]$ & 0.147 \\
\hline MMP16 & $1,691,707.088$ & {$[-3869174.848$ to $7,252,589.024]$} & 0.523 \\
\hline TIMP1 & $14,457.016$ & {$[-7526.012$ to $36,440.044]$} & 0.179 \\
\hline TIMP2 & 5262.861 & {$[-85597.990$ to $96,123.712]$} & 0.902 \\
\hline TIMP4 & $-47,199.665$ & {$[-445150.640$ to $350,751.311$} & 0.799 \\
\hline MMP2/TIMP1 Ratio & -79.725 & {$[-159.870$ to 0.419$]$} & 0.051 \\
\hline MMP2/TIMP2 Ratio & -30.903 & {$[-94.861$ to 33.056$]$} & 0.316 \\
\hline MMP9/TIMP1 Ratio & -330.433 & {$[-732.257$ to 71.391$]$} & 0.099 \\
\hline MMP2/TIMP4 Ratio & -0.345 & {$[-2.205$ to 1.516$]$} & 0.691 \\
\hline MMP16/TIMP4 Ratio & 7.394 & {$[-69.324$ to 84.111$]$} & 0.836 \\
\hline Serum TIMP1 & -0.004 & {$[-0.006$ to -0.001$]$} & 0.015 \\
\hline Serum TIMP2 & 0.028 & {$[-0.235$ to 0.292$]$} & 0.822 \\
\hline \multicolumn{4}{|l|}{ AoMG } \\
\hline Cardiomyocyte Area & 0.038 & {$[-0.059$ to 0.135$]$} & 0.421 \\
\hline Fibrosis & 9.331 & {$[-93.022$ to 111.684$]$} & 0.850 \\
\hline COLIA1 & $-248,924.745$ & [ -492536.116 to -5313.373$]$ & 0.046 \\
\hline COL3A1 & $-55,243.442$ & [- 128681.989 to $18,195.105]$ & 0.128 \\
\hline COL1A1/3A1 Ratio & -44.441 & {$[-87.659$ to -1.224$]$} & 0.045 \\
\hline MMP2 & -8256.311 & {$[-85857.707$ to $69,345.085]$} & 0.822 \\
\hline MMP9 & $-273,834.048$ & {$[-737776.442$ to $190,108.346]$} & 0.225 \\
\hline MMP16 & $1,163,548.388$ & {$[-1821928.808$ to $4,149,025.584]$} & 0.415 \\
\hline TIMP1 & 9237.603 & [-2320.881 to $20,796.086]$ & 0.108 \\
\hline TIMP2 & 8692.535 & {$[-40342.265$ to $57,727.334]$} & 0.708 \\
\hline TIMP4 & $-20,738.463$ & {$[-241638.087$ to $200,161.161]$} & 0.840 \\
\hline MMP2/TIMP1 Ratio & -44.416 & {$[-87.457$ to -1.375$]$} & 0.044 \\
\hline MMP2/TIMP2 Ratio & -20.424 & {$[-54.401$ to 13.554$]$} & 0.217 \\
\hline MMP9/TIMP1 Ratio & -157.431 & {$[-381.331$ to 66.470$]$} & 0.153 \\
\hline MMP2/TIMP4 Ratio & -0.215 & {$[-1.244$ to 0.815$]$} & 0.655 \\
\hline MMP16/TIMP4 Ratio & 0.796 & {$[-41.824$ to 43.416$]$} & 0.968 \\
\hline Serum TIMP1 & -0.002 & {$[-0.004$ to -0.0002$]$} & 0.031 \\
\hline Serum TIMP2 & 0.002 & {$[-0.166$ to 0.169$]$} & 0.983 \\
\hline \multicolumn{4}{|l|}{ AVA } \\
\hline Cardiomyocyte Area & -0.001 & {$[-0.002$ to $-2.6 \mathrm{E}-5]$} & 0.043 \\
\hline Fibrosis & -0.628 & {$[-1.749$ to 0.493$]$} & 0.251 \\
\hline COLIA1 & 4045.908 & [564.094 to 7527.721$]$ & 0.026 \\
\hline COL3A1 & 999.124 & [- 42.261 to 2040.509$]$ & 0.059 \\
\hline COL1A1/3A1 Ratio & 0.684 & [0.050 to 1.319$]$ & 0.037 \\
\hline MMP2 & 31.793 & [- 1153.160 to 1216.745$]$ & 0.954 \\
\hline MMP9 & 2748.383 & [- 4536.323 to $10,033.089]$ & 0.427 \\
\hline MMP16 & $-16,518.724$ & {$[-64280.280$ to $31,242.833]$} & 0.466 \\
\hline TIMP1 & -65.689 & [ -255.398 to 124.020$]$ & 0.465 \\
\hline TIMP2 & -118.969 & {$[-861.135$ to 623.197$]$} & 0.733 \\
\hline
\end{tabular}


Table 3 (continued)

\begin{tabular}{lcll}
\hline Variable & B coefficient & $\mathbf{9 5 \%} \mathbf{C l}$ & $\boldsymbol{p}$ value \\
\hline TIMP4 & -1791.725 & {$[-4921.305$ to 1337.855$]$} & 0.231 \\
MMP2/TIMP1 Ratio & 0.089 & {$[-0.678$ to 0.855$]$} & 0.806 \\
MMP2/TIMP2 Ratio & 0.309 & {$[-0.225$ to 0.843$]$} & 0.231 \\
MMP9/TIMP1 Ratio & 1.551 & {$[-2.011$ to 5.114$]$} & 0.361 \\
MMP2/TIMP4 Ratio & 0.009 & {$[-0.006$ to 0.023$]$} & 0.200 \\
MMP16/TIMP4 Ratio & 0.281 & {$[-0.326$ to 0.889$]$} & 0.326 \\
Serum TIMP1 & $8.697 \mathrm{E}-6$ & {$[2.4 \mathrm{E}-5$ to $4.1 \mathrm{E}-5]$} & 0.577 \\
Serum TIMP2 & -0.001 & {$[-0.004$ to 0.001$]$} & 0.303 \\
\hline
\end{tabular}

Results in bold represent $p<0.05$

AoMaxG aortic valve maximum gradient, AoMG aortic valve mean gradient, AVA aortic valve area, $C l$ confidence interval, $M M P$ matrix metalloproteinase, TIMP tissue inhibitor of metalloproteinase
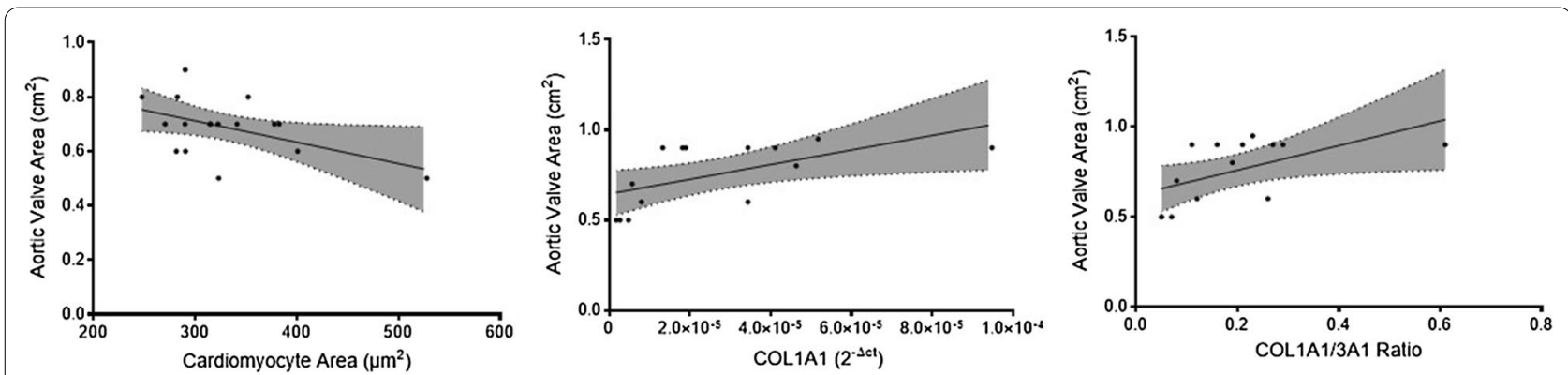

Fig. 7 Linear regression between Aortic Valve Area and atrial cardiomyocyte area and collagen type I and III gene expression. (All $p<0.05$ )
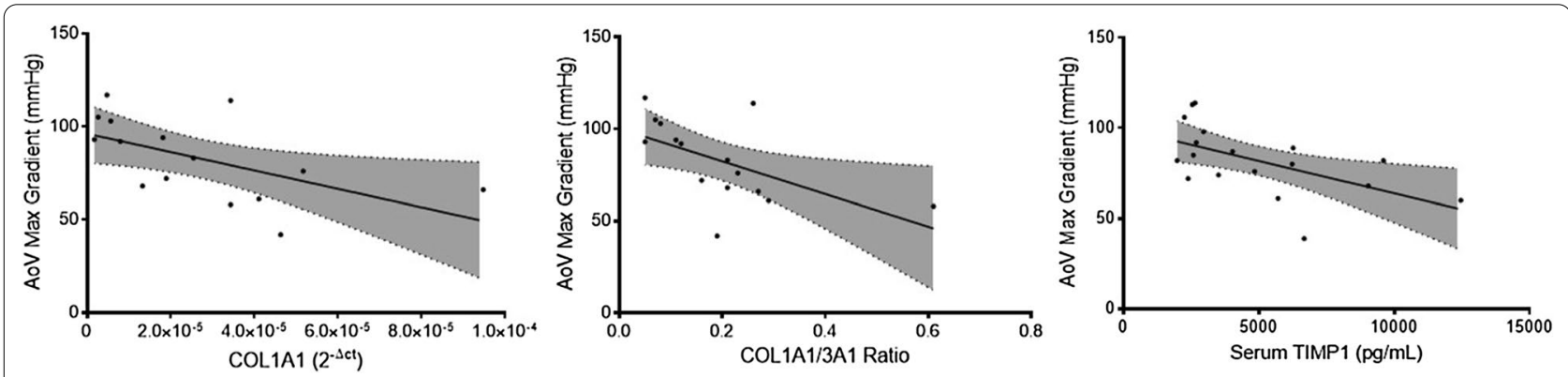

Fig. 8 Linear regression between aortic valve maximum gradient and collagen type I gene expression, collagen type I/III ratio gene expression and serum TIMP1 protein levels. (All $p<0.05)$

stimulating fibroblast proliferation which leads to cardiac fibrosis [18]. Fibroblast-cardiomyocyte coupling might slow conduction, therefore promoting re-entrance mechanisms, as well as enhance phase 4 depolarization, inducing ectopic impulse generation [19]. This cell-to-cell interaction depends on the degree of coupling, the number of coupled fibroblasts to each cardiomyocyte, and the relative size of cardiomyocytes versus fibroblasts [20]. Furthermore, the increased cardiomyocyte cell area in AF patients might correspond to a glycogen accumulation, with depletion of contractile material, as demonstrated in a study of sustained AF in goats with a substantial proportion of atrial myocytes with marked ultrastructure changes, including loss of myofibrils and accumulation of glycogen [21]. Studies on dogs with mitral valve stenosis have reported atrial cardiomyocyte hypertrophy with decreased myofibrils [21, 22]. Despite the absence of studies on aortic stenosis patients, it has been reported similar degenerative cardiomyocyte changes in patients submitted to cardiac surgery, which correlate with atrial size and pressure, along with diastolic dysfunction [23]. 

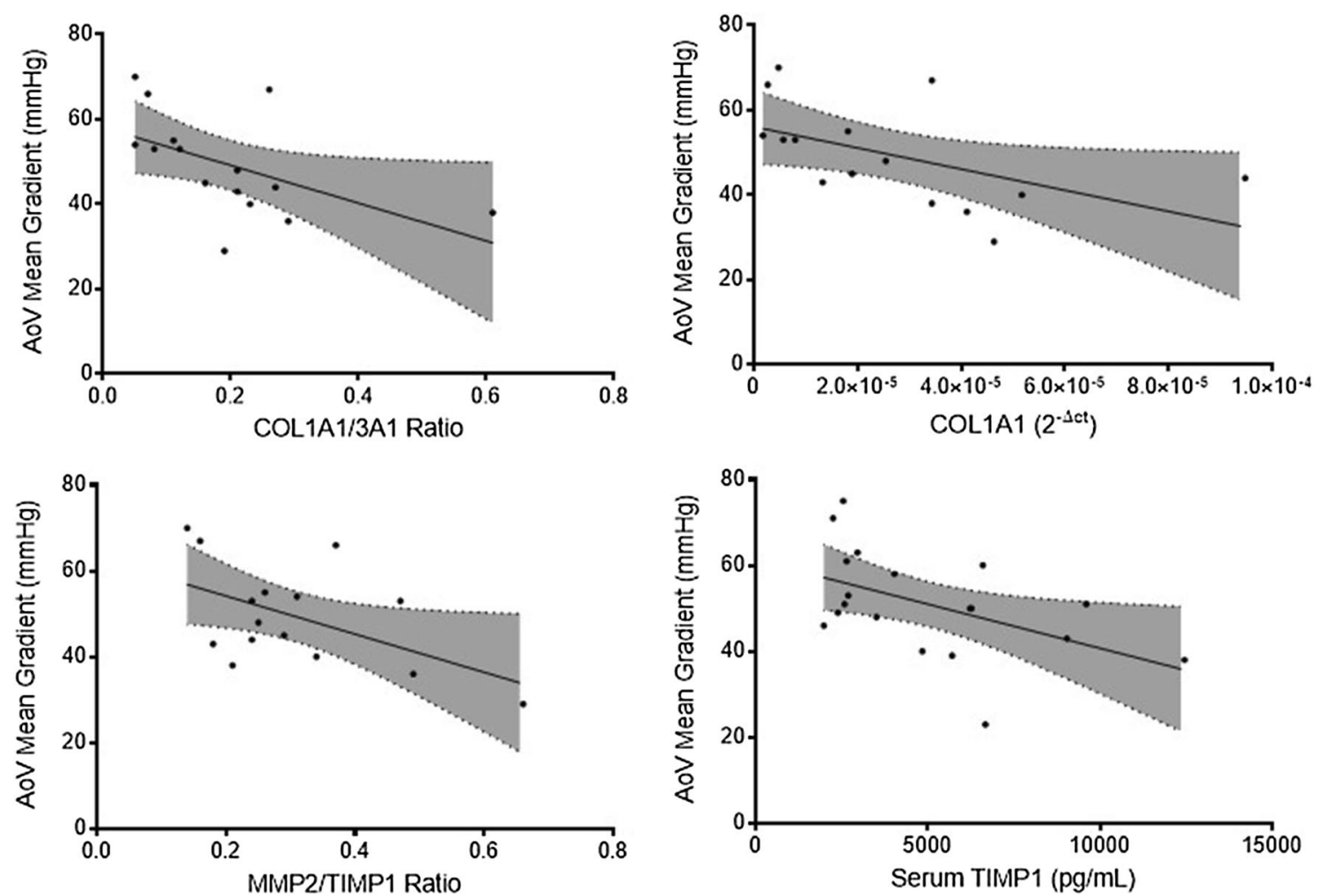

Fig. 9 Linear regression involving aortic valve mean gradient and collagen type I gene, collagen type I/III ratio gene expression, MMP2/TIMP1 gene expression ratio and serum TIMP1 protein quantification. (All $p<0.05$ )

In addition to the increase in atrial fibrosis in histology sections, mRNA expression of collagen type III was higher in AF patients, although collagen I and collagen I/III ratio did not present differences between groups. Zhang et al. reported an increase in atrial mRNA expression of collagen I and III in AF patients with rheumatic heart disease [24]. Likewise, Cao et al. reported a similar increase in patients with permanent AF undergoing valvular replacement [25]. Conversely, Yoshihara et al. found a decrease in mRNA expression of both collagen type I and III in patients with AF submitted to Kosakai's modified maze procedure [26]. The present study focused on AF patients with aortic stenosis submitted to valve replacement, which could explain the isolated increase in type III collagen gene expression between patient groups.

Regarding atrial extracellular matrix gene expression, TGF- $\beta 1$ was similar between groups. TGF $\beta 1$ is an established positive regulator of cardiac fibrosis [27], is upregulated in AF patients with mitral valve disease submitted to valve replacement, and [28] postoperative AF in patients submitted to myocardial revascularization [29]. Nevertheless, studies on aortic stenosis are scarce. MMP2, MMP9, and MMP16 showed no statistically significant differences between AF and SR patient subgroups. However, TIMP1 and TIMP2 were decreased in $\operatorname{AF}(p=0.052$ and $p=0.026$, respectively), with no differences in gene expression for TIMP4. Regarding MMP/TIMP ratios, MMP2/TIMP1, MMP2/TIMP2, and MMP9/TIMP1 were similar in AF participants when compared to their SR counterparts. Conversely, MMP2/ TIMP4 demonstrated a tendency towards significance, being decreased in AF patients, while MMP16/TIMP4 was significantly lower in this patient subgroup. Extracellular matrix remodeling is induced by collagen digestion through MMPs with tightly opposing inhibitors (TIMPs) [30]. Findings vary according to experimental conditions, target extracellular matrix proteins, type of cardiovascular disease, and AF progression [1]. Polyakova et al. found increased atrial expression of MMP2, MMP9, and TIMP1, although no differences in TIMP4, in AF patients submitted to a mini-Maze procedure [31]. Conversely, there were no differences in MMP9 atrial expression in AF patients with heart failure with reduced ejection fraction [32]. Despite a similar expression of TIMP4 between groups, MMP2/TIMP4 and MMP16/TIMP4 ratios demonstrated a decrease in AF patients. MMP2/ TIMP4 ratio has been reported to be increased in heart failure induced by occlusion of the left coronary artery 
in spontaneously hypertensive rats [33]. Additionally, Wetzl et al. found a correlation between MMP2/TIMP4 ratio and mean pulmonary arterial pressure, pulmonary vascular resistance, estimated glomerular filtration rate, and tricuspid annular plane systolic excursion. Remarkably, MMP16/TIMP4 was overwhelmingly decreased in AF patients. This is the first study that suggests MMP16/ TIMP4 as a marker of disease, specifically, a marker of chronic AF in aortic stenosis patients. Furthermore, although a significantly decreased atrial gene expression (TIMP1 and TIMP2) was observed, AF patients' serum TIMP1 and TIMP2 proteins were significantly increased. This might represent a downregulation of expression when considering increased protein levels. The increase in matrix inhibitors when comparing with proteolytic enzymes (decreased MMP/TIMP ratios) may explain the collagen accumulation seen by histology, in addition to the increased mRNA collagen type III expression.

Concerning aortic stenosis severity, Aortic Valve Maximum and Mean Gradients were negatively correlated with collagen type I gene expression, collagen type I/III ratio, and serum TIMP1 protein levels. Additionally, MMP2/TIMP1 ratio was inversely correlated with aortic valve mean gradient. Aortic valve area was positively correlated with collagen type I gene expression and collagen type I/III ratio. Moreover, aortic valve area was negatively associated with cardiomyocyte cell area. Although the classical aortic valve stenosis severity definition remains dependent on transthoracic echocardiography and its parameters, such as maximal aortic velocity (severe, $>4 \mathrm{~m} / \mathrm{s}$ ), mean pressure gradient (severe, $>40 \mathrm{mmHg}$ ) and aortic valve area (severe, $>1 \mathrm{~cm}^{2}$ ), the interplay between comorbidities and aortic stenosis risk of progression remains incompletely understood [34, 35]. AF in aortic stenosis is associated with lower maximum and mean pressure gradients, which could lead to a misclassification of disease severity, since AF represents an independent risk factor for adverse outcomes, including all-cause mortality [36]. The obstruction caused by aortic stenosis leads to pressure overload and, ultimately, to ventricular hypertrophy and cardiac fibrosis [37]. Azevedo et al. found the amount of myocardial fibrosis is associated with all-cause mortality after aortic valve replacement in patients with severe aortic stenosis, indicating tissue fibrosis could be a marker of disease severity [38]. Overall, our results indicate an adverse remodelling in patients with lower maximum and mean pressure gradients, which can be explained by the presence of AF in this cohort. AF patients have worse remodelling and lower gradients, thus patients with more collagen deposition will be those with, apparently, less severe stenosis. However, a higher degree of fibrosis is associated with worse outcomes. Our results suggest several matrix proteins which could be implicated in disease severity besides histological fibrosis. Serum TIMP1 could be a marker of adverse outcomes in aortic stenosis, in addition to conventional echocardiography.

This study indicates an atrial matrix remodeling in aortic stenosis patients with chronic AF submitted to valve replacement while suggesting TIMP1 and TIMP2 as biomarkers of disease, readily available with peripheral blood sampling. MMP16/TIMP4 ratio is increased in AF and potentially a novel marker of this arrhythmia. Although the number of patients analysed is relatively low and thus further studies on chronic AF are needed, this is the first study on atrial matrix remodelling in aortic stenosis patients with atrial fibrillation.

\section{Conclusions}

Atrial fibrillation patients with severe aortic stenosis present increased atrial fibrosis and collagen type III synthesis, with extracellular matrix remodelling demonstrated by a decrease in the MMP16/TIMP4 ratio, along with an increased serum TIMP1 and TIMP2 proteins. TIMP1 could be a marker of adverse outcomes in aortic stenosis, in addition to conventional echocardiography.

\section{Abbreviations \\ AF: Atrial fibrillation; AVR: Aortic valve replacement; CAD: Coronary artery disease; CICP: Collagen type 1 carboxy-terminal peptide; DAD: Delayed after- depolarizations; EKG: Electrocardiogram; ELISA: Enzyme-linked immunosorb- ent assay; MMP: Matrix metalloproteinase; NYHA: New York Heart Association; qPCR: Quantitative polymerase chain reaction; RT-PCR: Reverse transcription polymerase chain reaction; SR: Sinus rhythm; TGF- $\beta 1$ : Transforming growth factor $\beta 1$; TIMP: Tissue inhibitor of metalloproteinase.}

\section{Acknowledgements}

Not applicable.

\section{Authors' contributions}

MFM performed PCR, ELISA, histological and statistical analysis, collected the data, designed and wrote the article. IM performed PCR analysis and wrote the article. DM performed PCR analysis and reviewed the article. IB performed ELISA analysis and reviewed the article. CM performed the histological analysis and reviewed the article. APN wrote the article. IFP designed the study and reviewed the article. ALM designed the study and reviewed the article. All Authors read and approved the manuscript.

\section{Funding}

This study was supported by the Cardiovascular R\&D Center, financed by national funds through FCT_Fundação para a Ciência e Tecnologia, I.P., under the scope of the projects UID/IC/00051/2019 and UIDP/00051/2020, and Fundo Europeu de Desenvolvimento Regional (FEDER) through Compete 2020 - Programa Operacional Competitividade E Internacionalização (POCI), the project DOCNET (Norte-01-0145-FEDER-000003), supported by Norte Portugal regional operational programme (Norte 2020), under the Portugal 2020 partnership agreement, through the European Regional Development Fund (ERDF), the project NETDIAMOND (POCI-01-0145-FEDER-016385), supported by European Structural And Investment Funds, Lisbon's regional operational program 2020.

\section{Availability of data and materials}

The datasets used and/or analysed during the current study are available from the corresponding author on reasonable request. 


\section{Ethics approval and consent to participate}

The investigation conforms with the principles outlined in the Declaration of Helsinki. The protocol was approved by the institution's ethics committee ("Comissão de Ética para a Saúde do Centro Hospitalar de São João/Faculdade de Medicina da Universidade do Porto", Approval Number 35.17). Data confidentiality was assured. All participants gave written informed consent.

\section{Consent for publication}

Not applicable.

\section{Competing interests}

The authors declare that they have no competing interest.

\section{Author details}

${ }^{1}$ Cardiovascular Research and Development Center, Faculty of Medicine, University of Porto, Alameda Professor Hernani Monteiro, 4200 Porto, Portugal. 2 Department of Clinical Pathology, São João University Hospital Centre, Porto, Portugal. ${ }^{3}$ Department of Biomedicine, Unit of Anatomy, Faculty of Medicine, University of Porto, Porto, Portugal. ${ }^{4}$ EPIUnit, Instituto de Saúde Pública, University of Porto, Porto, Portugal.

Received: 27 August 2020 Accepted: 25 October 2020

Published online: 31 October 2020

\section{References}

1. Xintarakou A, Tzeis S, Psarras S, Asvestas D, Vardas P. Atrial fibrosis as a dominant factor for the development of atrial fibrillation: facts and gaps. Europace. 2020;22:342-51. https://doi.org/10.1093/europace/euaa009.

2. Kirchhof P, Benussi S, Kotecha D, Ahlsson A, Atar D, Casadei B, et al. ESC guidelines for the management of atrial fibrillation developed in collaboration with EACTS. Eur Heart J. 2016;37:2893-962. https://doi. org/10.1093/eurheartj/ehw210.

3. Ferrari E, Tozzi P, Hurni M, Ruchat P, Stumpe F, von Segesser LK. Primary isolated aortic valve surgery in octogenarians. Eur J Cardio-Thorac Surg. 2010;38:128-33. https://doi.org/10.1016/j.ejcts.2010.01.049.

4. Yilmaz MB, Erbay AR, Balci M, Guray Y, Cihan G, Guray U, et al. Atrial natriuretic peptide predicts impaired atrial remodeling and occurrence of late postoperative atrial fibrillation after surgery for symptomatic aortic stenosis. Cardiology. 2006;105:207-12. https://doi.org/10.1159/00009 1641.

5. Tarantini G, Mojoli M, Windecker S, Wendler O, Lefèvre T, Saia F, et al. Prevalence and impact of atrial fibrillation in patients with severe aortic stenosis undergoing transcatheter aortic valve replacement an analysis from the SOURCE XT prospective multicenter registry. JACC CardiovasC Interv. 2016. https://doi.org/10.1016/j.jcin.2016.01.037.

6. Li N, Chiang DY, Wang S, Wang Q, Sun L, Voigt N, et al. Ryanodine receptor-mediated calcium leak drives progressive development of an atrial fibrillation substrate in a transgenic mouse model. Circulation. 2014;129:1276-85. https://doi.org/10.1161/CIRCULATIONAHA.113.00661 1.

7. Iwasaki Y, Nishida K, Kato T, Nattel S. Atrial fibrillation pathophysiology Circulation. 2011;124:2264-74. https://doi.org/10.1161/CIRCULATIO NAHA.111.019893.

8. Spach MS, Boineau JP. Microfibrosis produces electrical load variations due to loss of side- to-side cell connections: a major mechanism of structural heart disease arrhythmias. PACE Pacing Clin Electrophysiol. 1997;20:397-413. https://doi.org/10.1111/j.1540-8159.1997.tb06199.x.

9. Kallergis EM, Manios EG, Kanoupakis EM, Mavrakis HE, Arfanakis DA, Maliaraki NE, et al. Extracellular matrix alterations in patients with paroxysmal and persistent atrial fibrillation. Biochemical assessment of collagen type-I turnover. J Am Coll Cardiol. 2008;52:211-5. https://doi. org/10.1016/j.jacc.2008.03.045.

10. Sun $Y$, Huang $Z Y$, Wang $Z H$, Li CP, Meng $X L$, Zhang $Y$ J, et al. TGF- $\beta 1$ and TIMP-4 regulate atrial fibrosis in atrial fibrillation secondary to rheumatic heart disease. Mol Cell Biochem. 2015;406:131-8. https://doi.org/10.1007/ s11010-015-2431-1.

11. Lang RM, Badano LP, Mor-Avi V, Afilalo J, Armstrong A, Ernande L, et al. Recommendations for cardiac chamber quantification by echocardiography in adults: an update from the American society of echocardiography and the European association of cardiovascular imaging. Eur Heart J Cardiovasc Imaging. 2015;16:233-71. https://doi. org/10.1093/ehjci/jev014.

12. 2016 ESC Guidelines for the diagnosis and treatment of acute and chronic heart failure|European Heart Journal|Oxford Academic n.d. https ://academic.oup.com/eurheartj/article/37/27/2129/1748921. Accessed 21 May 2020

13. Hua R, Adamczyk A, Robbins C, Ray G, Rose RA. Distinct patterns of constitutive phosphodiesterase activity in mouse sinoatrial node and atrial myocardium. PLoS One. 2012. https://doi.org/10.1371/journ al.pone.0047652.

14. Nortamo S, Ukkola O, Lepojärvi S, Kenttä T, Kiviniemi A, Junttila J, et al. Association of sST2 and hs-CRP levels with new-onset atrial fibrillation in coronary artery disease. Int J Cardiol. 2017;248:173-8. https://doi. org/10.1016/j.ijcard.2017.07.022.

15. Zahid S, Cochet H, Boyle PM, Schwarz EL, Whyte KN, Vigmond EJ, et al. Patient-derived models link re-entrant driver localization in atrial fibrillation to fibrosis spatial pattern. Cardiovasc Res. 2016. https://doi. org/10.1093/cvr/cvw073.

16. Kim S-J, Choisy SCM, Barman P, Zhang H, Hancox JC, Jones SA, et al. Atrial remodeling and the substrate for atrial fibrillation in rat hearts with elevated afterload. Circ Arrhythmia Electrophysiol. 2011;4:761-9. https:// doi.org/10.1161/CIRCEP.111.964783.

17. Pujadas S, Vidal-Perez R, Hidalgo A, Leta R, Carreras F, Barros A, et al. Correlation between myocardial fibrosis and the occurrence of atrial fibrillation in hypertrophic cardiomyopathy: a cardiac magnetic resonance imaging study. Eur J Radiol. 2010. https://doi.org/10.1016/j.ejrad.2009.12.012.

18. Hansen ML, Dahl JS, Scott Argraves W, Irmukhamedov A, Rasmussen LM. Aortic valve stenosis and atrial fibrillation influence plasma fibulin-1 levels in patients treated with coronary bypass surgery. Cardiology. 2013;126:202-6. https://doi.org/10.1159/000354217.

19. Zlochiver S, Muñoz V, Vikstrom KL, Taffet SM, Berenfeld O, Jalife J. Electrotonic myofibroblast-to-myocyte coupling increases propensity to reentrant arrhythmias in two-dimensional cardiac monolayers. Biophys J. 2008;95:4469-80. https://doi.org/10.1529/biophysj.108.136473.

20. MacCannell KA, Bazzazi H, Chilton L, Shibukawa Y, Clark RB, Giles WR. A mathematical model of electrotonic interactions between ventricular myocytes and fibroblasts. Biophys J. 2007;92:4121-32. https://doi. org/10.1529/biophysj.106.101410.

21. Ausma J, Wijffels M, Thoné F, Wouters L, Allessie M, Borgers M. Structural changes of atrial myocardium due to sustained atrial fibrillation in the goat. Circulation. 1997;96:3157-63. https://doi.org/10.1161/01. CIR.96.9.3157.

22. Boyden PA, Tilley LP, Pham TD, Liu SK, Fenoglio JJ, Wit AL. Effects of left atrial enlargement on atrial transmembrane potentials and structure in dogs with mitral valve fibrosis. Am J Cardiol. 1982;49:1896-908. https:// doi.org/10.1016/0002-9149(82)90208-9.

23. Luc M-R, Albert A, Pham TD, Hordof A, Fenoglio JJ, Malm JR, et al. The relationship of human atrial cellular electrophysiology to clinical function and ultrastructure. n.d.

24. Zhang YJ, Ma N, Su F, Liu H, Mei J. Increased TRPM6 expression in atrial fibrillation patients contribute to atrial fibrosis. Exp Mol Pathol. 2015;98:486-90. https://doi.org/10.1016/j.yexmp.2015.03.025.

25. Cao H, Xue L, Wu Y, Ma H, Chen L, Wang X, et al. Natriuretic peptides and right atrial fibrosis in patients with paroxysmal versus persistent atrial fibrillation. Peptides. 2010;31:1531-9. https://doi.org/10.1016/j.pepti des.2010.04.019.

26. Yoshihara F, Nishikimi T, Sasako Y, Hino J, Kobayashi J, Minatoya K, et al. Plasma atrial natriuretic peptide concentration inversely correlates with left atrial collagen volume fraction in patients with atrial fibrillation: plasma ANP as a possible biochemical marker to predict the outcome of the maze procedure. J Am Coll Cardiol. 2002;39:288-94. https://doi. org/10.1016/S0735-1097(01)01719-3.

27. Pellman J, Sheikh F. Atrial fibrillation: mechanisms, therapeutics, and future directions. Compr Physiol. 2015;5:649-65. https://doi.org/10.1002/ cphy.c140047.

28. Li Y, Jian Z, Yang ZY, Chen L, Wang XF, Ma RY, et al. Increased expression of connective tissue growth factor and transforming growth factor-beta-1 in atrial myocardium of patients with chronic atrial fibrillation. Cardiology. 2013;124:233-40. https://doi.org/10.1159/000347126. 
29. Rahmutula D, Marcus GM, Wilson EE, Ding C-H, Xiao Y, Paquet AC, et al. Molecular basis of selective atrial fibrosis due to overexpression of transforming growth factor-b1. Cardiovasc Res. 2013. https://doi.org/10.1093/ cvr/cvt074.

30. Nattel S. Molecular and cellular mechanisms of atrial fibrosis in atrial fibrillation. JACC Clin Electrophysiol. 2017;3:425-35. https://doi.org/10.1016/j. jacep.2017.03.002

31. Polyakova V, Miyagawa S, Szalay Z, Risteli J, Kostin S. Atrial extracellular matrix remodelling in patients with atrial fibrillation. J Cell Mol Med. 2008;12:189-208. https://doi.org/10.1111/j.1582-4934.2008.00219.x.

32. Molina CE, Abu-Taha IH, Wang Q, Roselló-Díez E, Kamler M, Nattel S, et al. Profibrotic, electrical, and calcium-handling remodeling of the atria in heart failure patients with and without atrial fibrillation. Front Physiol. 2018. https://doi.org/10.3389/fphys.2018.01383.

33. Seeland U, Kouchi I, Zolk O, Itter G, Linz W, Böhm M. Effect of ramipril and furosemide treatment on interstitial remodeling in post-infarction heart failure rat hearts. J Mol Cell Cardiol. 2002;34:151-63. https://doi. org/10.1006/jmcc.2001.1497.

34. Baumgartner H, Hung J, Bermejo J, Chambers JB, Edvardsen T, Goldstein $S$, et al. Recommendations on the echocardiographic assessment of aortic valve stenosis: a focused update from the European Association of Cardiovascular Imaging and the American Society of Echocardiography. J Am Soc Echocardiogr. 2017;30:372-92. https://doi.org/10.1016/j. echo.2017.02.009.
35. Donal E, Dweck MR, Galli E. Definition of severe aortic stenosis: 'Awise man points at themoon, the fool looks at the finger' (Chinese proverb). Eur Heart J Cardiovasc Imaging. 2020;744:6. https://doi.org/10.1093/ehjci/ jeaa087.

36. Burup Kristensen C, Jensen JS, Sogaard P, Carstensen HG, Mogelvang R. Atrial fibrillation in aortic stenosis-echocardiographic assessment and prognostic importance. Cardiovasc Ultrasound. 2012;10:38. https://doi. org/10.1186/1476-7120-10-38.

37. Galat A, Guellich A, Bodez D, Lipskaia L, Moutereau S, Bergoend E, et al. Causes and consequences of cardiac fibrosis in patients referred for surgical aortic valve replacement. ESC Heart Fail. 2019;6:649-57. https://doi. org/10.1002/ehf2.12451.

38. Azevedo CF, Nigri M, Higuchi ML, Pomerantzeff PM, Spina GS, Sampaio $\mathrm{RO}$, et al. Prognostic significance of myocardial fibrosis quantification by histopathology and magnetic resonance imaging in patients with severe aortic valve disease. J Am Coll Cardiol. 2010;56:278-87. https://doi. org/10.1016/j.jacc.2009.12.074.

\section{Publisher's Note}

Springer Nature remains neutral with regard to jurisdictional claims in published maps and institutional affiliations.
Ready to submit your research? Choose BMC and benefit from:

- fast, convenient online submission

- thorough peer review by experienced researchers in your field

- rapid publication on acceptance

- support for research data, including large and complex data types

- gold Open Access which fosters wider collaboration and increased citations

- maximum visibility for your research: over 100M website views per year

At BMC, research is always in progress.

Learn more biomedcentral.com/submissions 